\title{
Smad gene expression in pulmonary fibroblasts: indications for defective ECM repair in COPD
}

\author{
Andre Zandvoort ${ }^{1,2}$, Dirkje S Postma², Marnix R Jonker ${ }^{1,2}$, \\ Jacobien A Noordhoek ${ }^{2}$, Johannes TWM Vos ${ }^{1}$ and Wim Timens*1
}

\author{
Address: ${ }^{1}$ Department of Pathology, University Medical Center Groningen, University of Groningen, Hanzeplein 1, NL-9713 GZ Groningen, The \\ Netherlands and 2Department of Pulmonology, University Medical Center Groningen, University of Groningen, Hanzeplein 1, NL-9713 GZ \\ Groningen, The Netherlands \\ Email: Andre Zandvoort - a.zandvoort@med.umcg.nl; Dirkje S Postma - d.s.postma@int.umcg.nl; Marnix R Jonker - m.r.jonker@path.umcg.nl; \\ Jacobien A Noordhoek - j.a.noordhoek@med.umcg.nl; Johannes TWM Vos - j.t.w.m.vos@path.umcg.nl; \\ Wim Timens* - w.timens@path.umcg.nl \\ * Corresponding author
}

Published: 16 December 2008

Respiratory Research 2008, 9:83

This article is available from: http://respiratory-research.com/content/9/1/83

(c) 2008 Zandvoort et al; licensee BioMed Central Ltd.

This is an Open Access article distributed under the terms of the Creative Commons Attribution License (http://creativecommons.org/licenses/by/2.0), which permits unrestricted use, distribution, and reproduction in any medium, provided the original work is properly cited.
Received: 10 April 2008

Accepted: 16 December 2008

\begin{abstract}
Background: Chronic Obstructive Pulmonary Disease (COPD) is characterized by defective extracellular matrix (ECM) turnover as a result of prolonged cigarette smoking. Fibroblasts have a central role in ECM turnover. The TGF $\beta$ induced Smad pathway provides intracellular signals to regulate ECM production. We address the following hypothesis: fibroblasts have abnormal expression of genes in the Smad pathway in COPD, resulting in abnormal proteoglycan modulation, the ground substance of ECM.
\end{abstract}

Methods: We compared gene expression of the Smad pathway at different time points after stimulation with TGF $\beta$, TNF or cigarette smoke extract (CSE) in pulmonary fibroblasts of GOLD stage II and IV COPD patients, and controls.

Results: Without stimulation, all genes were similarly expressed in control and COPD fibroblasts. TGF $\beta$ stimulation: downregulation of Smad3 and upregulation of Smad7 occurred in COPD and control fibroblasts, indicating a negative feedback loop upon TGF $\beta$ stimulation. CSE hardly influenced gene expression of the TGF $\beta$-Smad pathway in control fibroblasts, whereas it reduced Smad3 and enhanced Smad7 gene expression in COPD fibroblasts. Furthermore, decorin gene expression decreased by all stimulations in COPD but not in control fibroblasts.

Conclusion: Fibroblasts of COPD patients and controls differ in their regulation of the Smad pathway, the contrast being most pronounced under CSE exposure. This aberrant responsiveness of COPD fibroblasts to CSE might result in an impaired tissue repair capability and is likely important with regard to the question why only a subset of smokers demonstrates an excess ECM destruction under influence of cigarette smoking. 


\section{Introduction}

Chronic Obstructive Pulmonary Disease (COPD) is a severe, slowly progressive and disabling disease associated with accelerated lung function decline. COPD consists of emphysema, small airways disease, and chronic bronchitis, which may be present alone or in combination of different intensities. Emphysema is due to an extensive extracellular matrix (ECM) destruction of lung parenchyma [1-5]. In addition, emphysema can coincide with fibrosis of the airways as observed in chronic bronchitis and small airways disease [1,6-8]. The generally held hypothesis is that cigarette smoke induces an excess in extracellular matrix (ECM) degrading enzymes and reactive oxygen species that subsequently lead to ECM destruction of lung parenchyma [1]. We here propose a third important contributing factor to COPD development, i.e. an aberrant fibroblast function that contributes to disturbance of ECM homeostasis.

Pulmonary fibroblasts are essential cells in tissue repair processes since they are key producers of ECM constituents [9]. TGF $\beta$ is the main cytokine that stimulates fibroblasts to produce ECM constituents like decorin, biglycan, versican, and collagens [10]. The production of ECM components is inhibited by pro-inflammatory cytokines like TNF and IFN-gamma [11]. We have demonstrated previously that lung tissue of COPD patients contains less decorin, an important proteoglycan of the ECM $[9,12]$. In addition, our studies have shown that pulmonary fibroblasts of COPD patients with GOLD stage IV (very severe COPD[13]) produce less decorin after TGF $\beta$ stimulation than those of controls [14]. We hypothesize that this results from a defect or alteration in gene expression of the Smad pathway, since this regulates transcription of ECM proteins like collagens, decorin, versican and biglycan [11,15-17]. Smads are intracellular signal transducers transporting the TGF $\beta$ activation signal from the receptor to the nucleus in order to initiate gene transcription of ECM constituents [11,18-20] (Figure 1). TGF $\beta$ interacts with the TGF $\beta$ receptor II which in turn activates TGF $\beta$ receptor I. This activated TGF $\beta$ receptor complex induces phosphorylation of the Smad2-Smad3 complex that can interact with the transporter Smad4. The resulting complex enters the nucleus and initiates gene transcription of ECM constituents. Smad7 on the other hand can affect this pathway by inhibiting phosphorylation of Smad2 and Smad3 and inducing ubiquination of their receptors. Additionally, Smad7 can induce TGF $\beta$-production by fibroblasts upon activation by pro-inflammatory cytokines like TNF and IFN-gamma, thereby enabling autocrine stimulation that counterbalances superfluous Smad7 effects [21].

Ideally, fibroblasts should be capable of repairing cigarette smoke induced lung damage. This repair process appears inadequate in a subset of smokers, leading to gradually increasing parenchymal ECM destruction and emphysematous changes [9]. We addressed three questions to obtain more insight in the underlying mechanisms of this selective susceptibility, following our hypothesis that the Smad pathway is involved. Because of the limited knowledge on gene modulation of the Smad pathway we first addressed the question how Smad pathway genes are regulated in control fibroblasts under influence of TGF $\beta$, TNF and cigarette smoke components. We compared fibroblasts of COPD patients and controls as to their basal expression of Smad pathway genes. Finally, we investigated whether TGF $\beta$, TNF and CSE, stimuli that are of prime importance to fibroblast functioning $[1,2,22,23]$, stimulate the Smad pathway differently in primary fibroblast cultures of COPD patients and controls. To analyze Smad gene expression, fibroblasts were harvested 1 hour, and 24 hours after incubation with TGF $\beta$, TNF or CSE. Expression of Smad pathway related genes were analyzed by real-time PCR. As functional readout of Smad gene regulation, we determined gene expression of decorin, versican, and biglycan (Figure 1), ECM proteoglycans that are relevant to the development of COPD.

\section{Patients and methods Study design}

To answer the question whether genes of the Smad pathway are differentially expressed in COPD and controls, we stimulated primary fibroblasts of patients with stage II and stage IV COPD and controls with TGF $\beta$, TNF and cigarette smoke extract (CSE) for 1, and 24 hours. Primary fibroblasts were cultured from lung tissue, obtained from 23 individuals. Classification of COPD severity was based on the 2003 Global initiative for chronic obstructive lung disease (GOLD) criteria [13]. Three groups were made: Individuals with moderate (GOLD stage II, $\mathrm{n}=9$ ), and with very severe COPD (stage IV, $\mathrm{n}=9$ ), and individuals with histological normal lungs $(\mathrm{n}=5)$. Patients did not show clinical signs of chronic bronchitis and were not $\alpha_{1}$ antitrypsin deficient. Emphysema was assessed by routine histological examination of lung tissue, performed by an experienced pulmonary pathologist (WT). The clinical characteristics of the groups are presented in table 1. Informed consent was obtained from all patients. The study protocol was consistent with national ethical and professional guidelines ("Code of Conduct; Dutch Federation of Biomedical Scientific Societies"; http://www.fed era.org).

Tissue of GOLD stage II COPD patients (median $\mathrm{FEV}_{1}$ $73 \%$ of predicted) was derived from non-involved lung tissue from patients undergoing resective surgery for pulmonary carcinoma. Tissue was always taken as far as possible from the tumor, or from a non-involved lobe. 


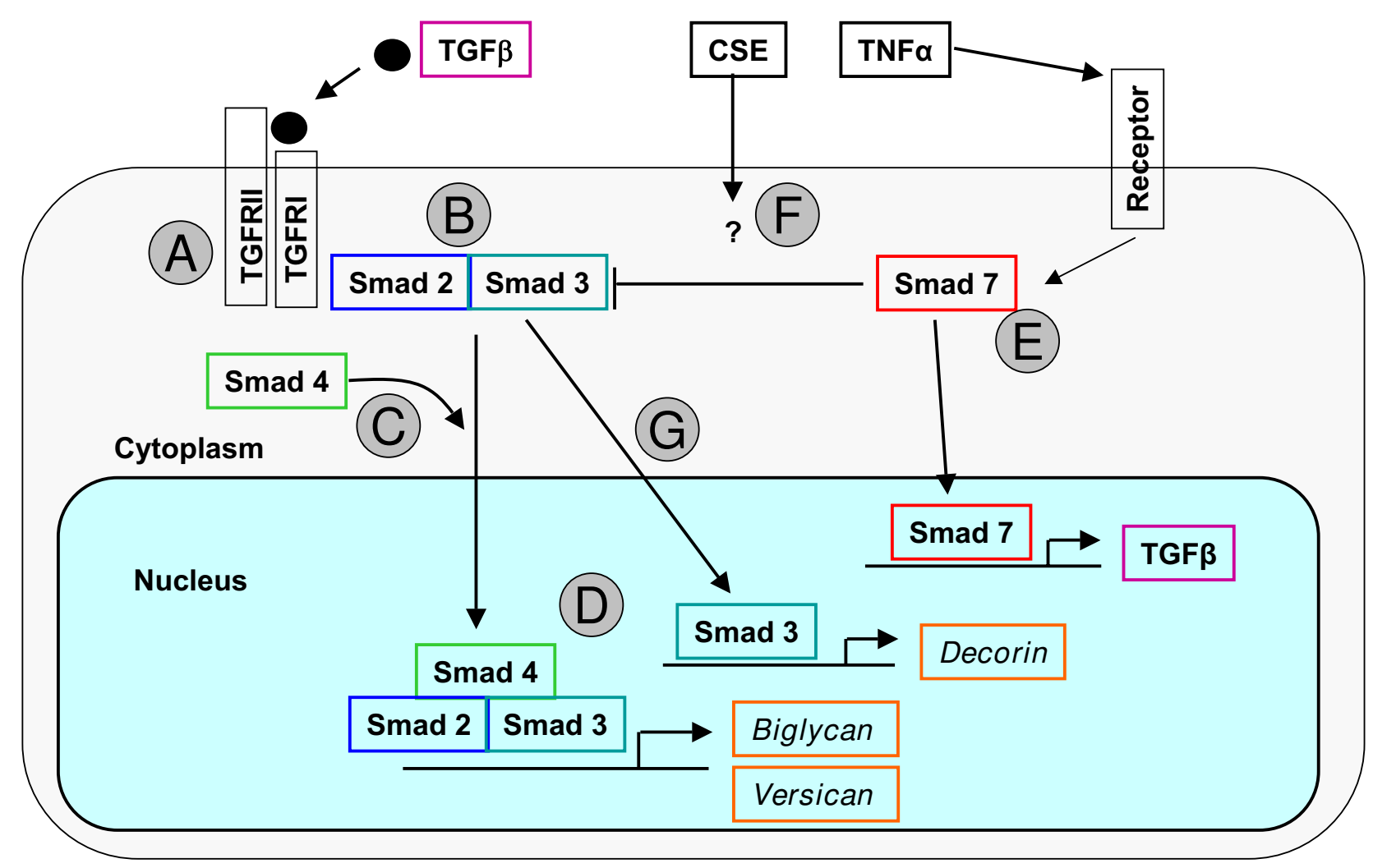

Figure I

Simplified schematic drawing of the TGF- $\beta$-Smad pathway. Binding of TGF- $\beta$ to its type II receptor in concert with the type I receptor $(A)$ leads to formation of a receptor complex and phosphorylation of the type I receptor. The type I receptor subsequently phosphorylates Smad2 or 3 (B), allowing this complex to associate with Smad4 and move into the nucleus (C). In the nucleus, the Smad complex associates with a transcription factor and this complex binds to specific enhancers in target genes (down-) regulating transcription (D). TNF is able to interfere with TGF- $\beta$ signaling through the upregulation of the inhibitory Smad7 protein (E). Smad7 is capable of inhibiting the Smad2 and 3 phosphorylating process by competing with the receptor interaction but Smad7 also can dephosphorylate the complex. In addition, Smad7 itself is capable to upregulate TGF $\beta$ gene expression. As described in the discussion, CSE is most likely capable to interfere with the Smad pathway although this is not yet fully elucidated. (F). Phosphorylated Smad3 is able to stimulate the transcription of the decorin gene (G). Adapted from $[18,19,35,36]$.

Histopathologically emphysematous lesions were present, yet of limited but varying severity. The moderate forms can be histopathologically demonstrated by the finding of isolated or free-lying segments of viable alveolar septal tissue or isolated cross sections of pulmonary vessels $[19,20]$.

Tissue of GOLD stage IV COPD patients (median $\mathrm{FEV}_{1}$ $19 \%$ of predicted) was obtained from COPD patients undergoing surgery for lung transplantation or lung volume reduction. All individuals had quitted smoking for at least 1 year before surgery. The resected tissue showed both macroscopically and microscopically severe emphysematous lesions, often accompanied by bullae. Sub-pleural fibrous areas were avoided.
Tissue of the control group (median $\mathrm{FEV}_{1} 86 \%$ of predicted) was derived from non-involved lung tissue from patients undergoing resective surgery for pulmonary carcinoma. Patients had no airway obstruction, nor chronic airway symptoms like cough and sputum production. Material was always taken as far as possible from the tumor, or from a non-involved lobe. No histopathological abnormalities were present.

\section{Isolation and culture of lung fibroblasts}

Pulmonary fibroblast cultures were established from parenchymal lung tissue by explant technique. Absence of mycoplasma contamination in the fibroblast cultures was confirmed with a mycoplasma detection kit (Roche Diagnostics, Almere, The Netherlands). Isolated cells were 
Table I: Characteristics of the control and patient groups

\begin{tabular}{llll}
\hline & Control & Stage II & Stage IV \\
\hline Number of subjects & 5 & 9 & 9 \\
Age (years) & $62(36-63)$ & $70(44-8 I)$ & $55(44-6 I)$ \\
Smoking (Ex/C) & $2 / 3$ & $5 / 4$ & $9 / 0$ \\
Pack-years & $13(0-75)$ & $30(8-58)$ & $30(17-54)$ \\
FEV $\%$ predicted & $86(83-108)$ & $73(50-76)$ & $19(13-29)$ \\
FEV $/$ /FVC \% pred & $73(70-8 I)$ & $55(37-68)$ & $35(24-66)$
\end{tabular}

All values are presented as median values with ranges in parentheses. $\mathrm{Ex}=$ ex smokers, not smoking for at least one year, $\mathrm{C}=$ current smokers; FEV $\%$ predicted $=$ Forced Expiratory Volume in I second as percentage of predicted value; FVC = forced vital capacity; pred $=$ predicted. Stage means severity of COPD according to GOLD criteria.

characterized as fibroblasts by morphological appearance and expression pattern of specific proteins as described previously [24]. Fibroblast cultures were stored into liquid nitrogen until use.

Fibroblast cultures cultured in complete culture medium (Ham's F12, 10\%FBS, penicillin, streptavidin and glutamin (all from Cambrex, Verviers, Belgium)). Experiments were performed on fibroblasts of passage 5/6 with confluent growth. After reaching confluence, fibroblasts were cultured for $24 \mathrm{~h}$ on $0.5 \%$ FBS culture medium before the stimulations started. Cells were washed with Ham's culture medium without FBS and incubated with the appropriate stimulus, diluted in complete culture medium. TGF $\beta$ (R\&D systems, Abingdon, UK) was used in a concentration of $100 \mathrm{u} / \mathrm{ml}$, TNF (R\&D systems) in a concentration of $1000 \mathrm{u} / \mathrm{ml}$ and CSE was used in a concentration of $2.5 \%$. CSE was prepared according to a standardized protocol by bubbling the puffs of 4 cigarettes (Kentucky University research cigarettes) through $50 \mathrm{ml}$ of Ham's F12 (Cambrex). The medium was filter sterilized with a 22 um filter. After the designated duration of the stimulation ( 1 and 24 hours) cells were harvested by trypsinization (Trypsin, Cambrex) followed by two wash steps. Non-stimulated fibroblasts were also harvested at $1 \mathrm{~h}$ and $24 \mathrm{~h}$ for comparison of effect of stimulation. Cell pellets were lysed using lysis buffer of the RNeasy mini kit for RNA isolation (Qiagen, Hilden, Germany). Optimal concentrations and durations of the stimulation were determined in previous experiments (data not shown). As a check for an adequate effect of TGF $\beta$ stimulation, expression of plasminogen activator inhibitor (PAI)-1, being a classical TGF $\beta$ regulated gene, was analyzed, similar to the other genes. PAI- 1 was significantly upregulated by TGF $\beta$ in all fibroblast samples tested.

\section{Real time PCR}

Fibroblast total RNA was isolated using the RNeasy mini kit (Qiagen). RNA quantity and quality (OD 260/280) were determined by optical density measurements on the
Nanodrop. Total RNA was treated with DNase I during RNA isolation and run over the column to remove genomic DNA (Qiagen RNA-se free DNAse set). Three ng mRNA was transcribed into cDNA by reverse transcriptase II (Invitrogen, Breda, the Netherlands). Real time PCR was performed on an ABI7900 HT sequencer with "Assay on Demands" from Applied Biosystems (Foster City, CA, USA), according to the manufacturers' instructions. Expression of the following genes was analyzed: Smad2, $3,4,7$, versican, biglycan, and decorin. Data were analyzed by the delta-delta-Ct method [25]. In brief, concentration in time $(\mathrm{Ct})$ values of the genes of interest were corrected for Ct values from a housekeeping gene, resulting in a delta-Ct value. In case of stimulation, the obtained delta-Ct was normalized to the delta-Ct of the non-stimulated sample value at the same time point (delta-delta-Ct). The $2^{\text {-delta-delta-Ct }}$ was taken for each stimulated fibroblast sample, which was compared to its unstimulated counterpart and presented as a percentage of this basal value; each basal values was set to $100 \%$. Several housekeeping genes were tested for the influence of the experimental procedure on the expression. Ribosomal protein S9 was chosen as most optimal household gene because gene expression was most stable under basal as well as stimulation conditions.

\section{Statistical analysis}

Differences in subject characteristics and real time data between the gene expression at basal levels were analyzed using the Kruskal-Wallis test followed by the Mann-Whitney U test. Differences between gene expression after stimulation were analyzed using the Wilcoxon signed rank test. To analyze differences between COPD- and control fibroblasts, we calculated the percent change from the stimulated value as compared to the basal value. Significant differences in this percent change between COPD fibroblasts and controls were also analyzed using the Kruskal-Wallis test followed by a Mann-Whitney U test. The level of significance used was $<0.05$, all reported Pvalues are two-sided.

\section{Results \\ Influence of TGF $\beta$, TNF, and CSE on Smad pathway related gene expression in fibroblasts \\ Healthy individuals \\ TGF $\beta$ stimulation}

Downregulation of Smad3 gene expression occurred at 24-hour stimulation, while Smad2, Smad4, biglycan and versican gene expression were upregulated (figures 2 and 3; additional file 1). Smad7 gene expression was upregulated by TGF $\beta$ at both 1 -hour and 24 -hour stimulation.

\section{TNF stimulation}

Upregulation of Smad 2 and 7 gene expression occurred at 24-hour stimulation. Smad4 was upregulated at both 1hour and 24-hour stimulation. Biglycan was downregu- 

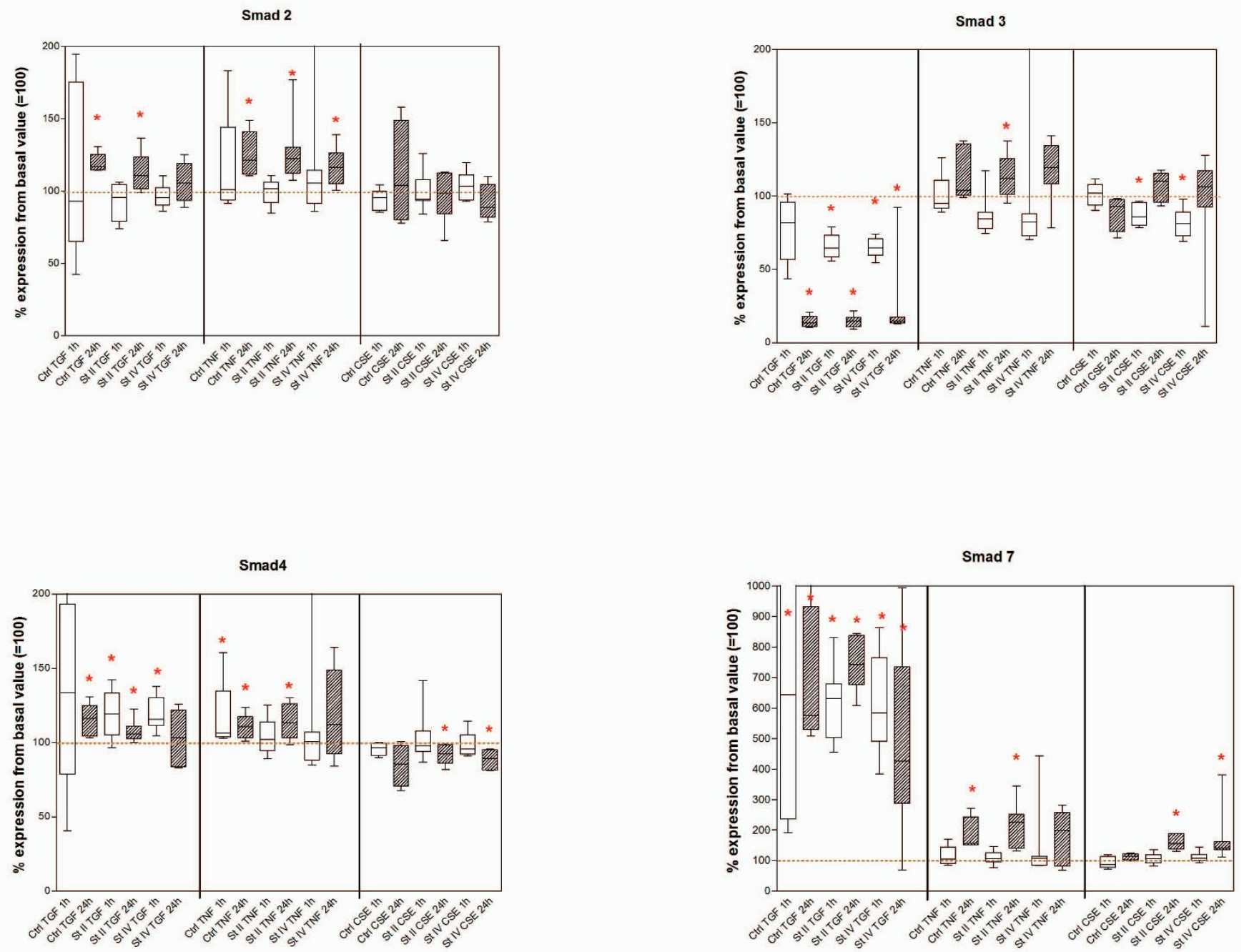

Figure 2

Smad2, 3, 4 and 7: Results of real-time PCR analysis at I and $24 \mathrm{~h}$, presented for control and disease stage, per stimulation. Values are based on 2-delta-delta-Ct values and represent the median percentages compared to the basal value before each stimulation (basal set to $100 \%$ ). Asterisks indicate significant change compared to basal values. St II = GOLD stage II, St IV = GOLD stage IV.

lated after 1 hour. Versican gene expression was downregulated at 24-hour stimulation (figures 2 and 3).

\section{CSE}

No effect on Smad genes occurred. The genes for biglycan, decorin, and versican were downregulated after 1 hour of exposure, without an effect at 24 hours.

\section{COPD GOLD stage II patients}

TGF $\beta$ stimulation

Whereas Smad3 gene expression in COPD stage II fibroblasts was significantly downregulated at 1 - and 24-hour stimulation (figures 2 and 3; additional file 1), Smad4 and Smad7 gene expression was upregulated, Smad2 was upregulated only at 24 hours. Decorin gene expression was significantly downregulated at 24-hour stimulation, whereas biglycan and versican gene expression was upregulated at 24 hours.

\section{TNF stimulation}

All Smads were significantly upregulated at 24 hours. Decorin expression was downregulated at both 1- and 24hour stimulation. Biglycan gene expression was downregulated at 1 hour and versican gene expression was downregulated at 24 hours.

\section{CSE exposure}

Smad3 and decorin gene expression was downregulated at 1 hour. Smad4, decorin and biglycan gene expression was downregulated at 24 hours. Smad7 gene expression was upregulated at 24-hour stimulation. 

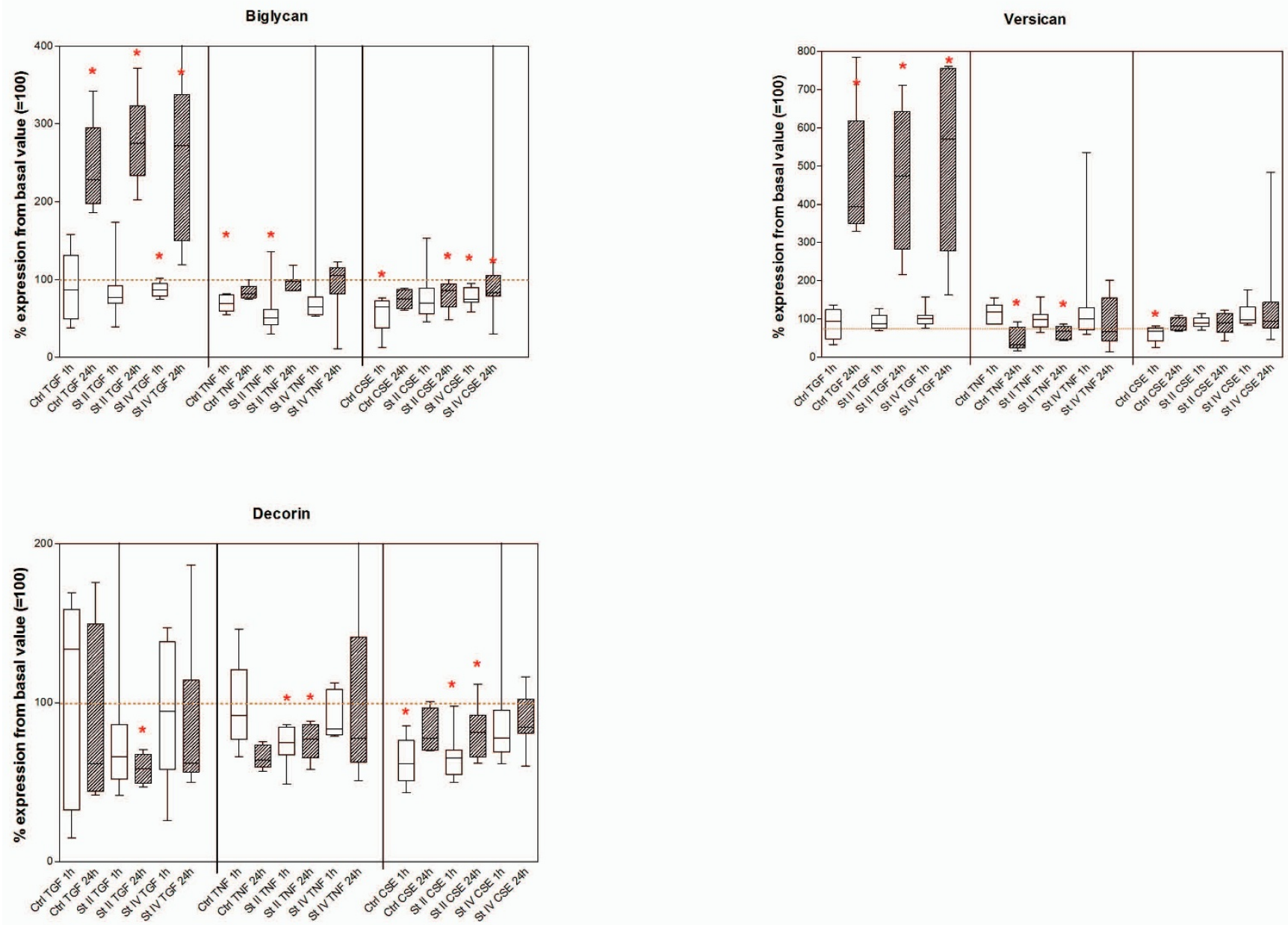

\section{Figure 3}

Decorin, biglycan and versican: Results of real-time PCR analysis at I and $24 \mathrm{~h}$, presented for control and disease stage, per stimulation. Values are based on $2^{\text {-delta-delta-Ct }}$ values and represent the median percentages compared to the basal value before each stimulation (basal set to I00\%). Asterisks indicate significant change compared to basal values. St II = GOLD stage II, St IV = GOLD stage IV.

\section{COPD GOLD stage IV patients}

\section{TGF $\beta$ stimulation}

Smad3 gene expression was downregulated at both time points, while Smad7 gene expression was upregulated; Smad4 was upregulated at 1 hour. Biglycan gene expression was downregulated at 1 hour, whereas biglycan and versican gene expression was upregulated at 24-hour TGF $\beta$ stimulation.

\section{TNF stimulation}

TNF resulted in upregulation of Smad2 gene expression at 24-hour stimulation.

\section{CSE exposure}

CSE exposure resulted in a downregulation of Smad3 gene expression after 1 hour of stimulation, while biglycan gene expression was also downregulated at that time point. Smad4 and biglycan were downregulated and Smad7 gene expression was upregulated at 24 hours after CSE exposure.

\section{Differences in Smad pathway gene expression between COPD and control fibroblasts}

To specifically analyze the differential expression between COPD fibroblasts and control fibroblasts, we calculated the percentage change in gene expression after stimulation from its basal value for each subject group. Subsequently we checked for differences in strength of the stimulation effect between controls and COPD fibroblasts by determining the difference between the change in gene expression from control fibroblasts when compared to stage II and IV COPD fibroblasts, respectively (figure 4). 
Without stimulation, gene expression levels were similar between COPD and control fibroblasts. Smad2 and Smad4 gene expression showed no differential expression between COPD and control fibroblasts at all. Genes that were differentially expressed between COPD and control fibroblasts after stimulation with TGF $\beta$, TNF or CSE are depicted in figure 4 . Smad3 gene expression decreased significantly more in fibroblasts from COPD patients than from controls at 1 hour after TNF as well as CSE exposure (figure 4A). Smad7 gene expression was significantly more increased in COPD than control fibroblasts after 24 hours CSE exposure (figure 4B). Versican gene expression was significantly less decreased in COPD Stage II and IV than control fibroblasts at 1 hour after CSE exposure (figure 4C). Decorin gene expression was significantly more reduced in stage IV than the other group fibroblasts after TGF $\beta$-stimulation, whereas an increase was observed in controls (figure 4D).
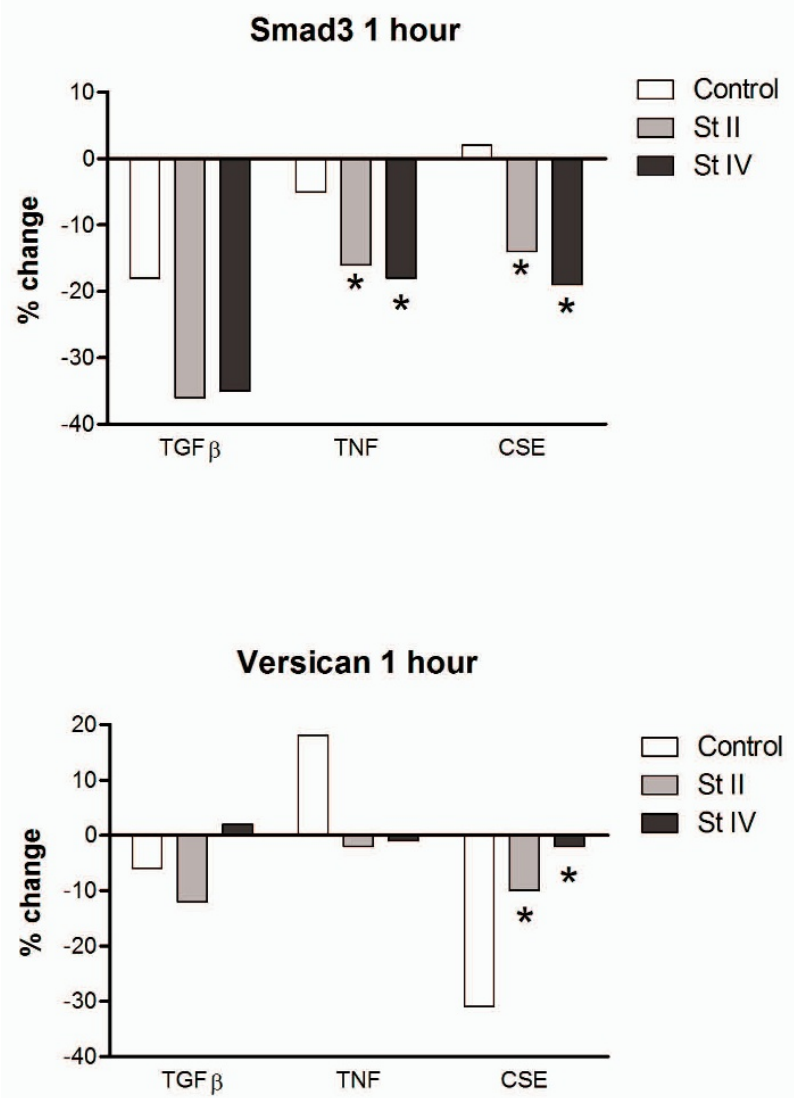

\section{Discussion}

We addressed the question whether genes of the Smad pathway are aberrantly expressed in COPD fibroblasts with and without TGF $\beta$, TNF, and cigarette smoke extract (CSE) stimulation. We provide suggestive evidence that this is indeed the case. Since the Smad pathway coordinates a delicate balance between fibrosis and excess ECM destruction, alterations in this pathway can contribute to the development of COPD. All investigated genes were similarly expressed in control and COPD fibroblasts without stimulation. In contrast, we observed a stimulus dependent gene expression of the Smad pathway with differential expression in COPD and control fibroblasts. In particular Smad3 and Smad7 were aberrantly regulated in COPD fibroblasts under influence of TNF and CSE (figure $4)$. Moreover, the ECM proteoglycans decorin and biglycan were downregulated in COPD fibroblasts after 24 hours of CSE exposure.

Little is known about the regulation of Smad and ECM gene expression in lung tissue fibroblasts of COPD
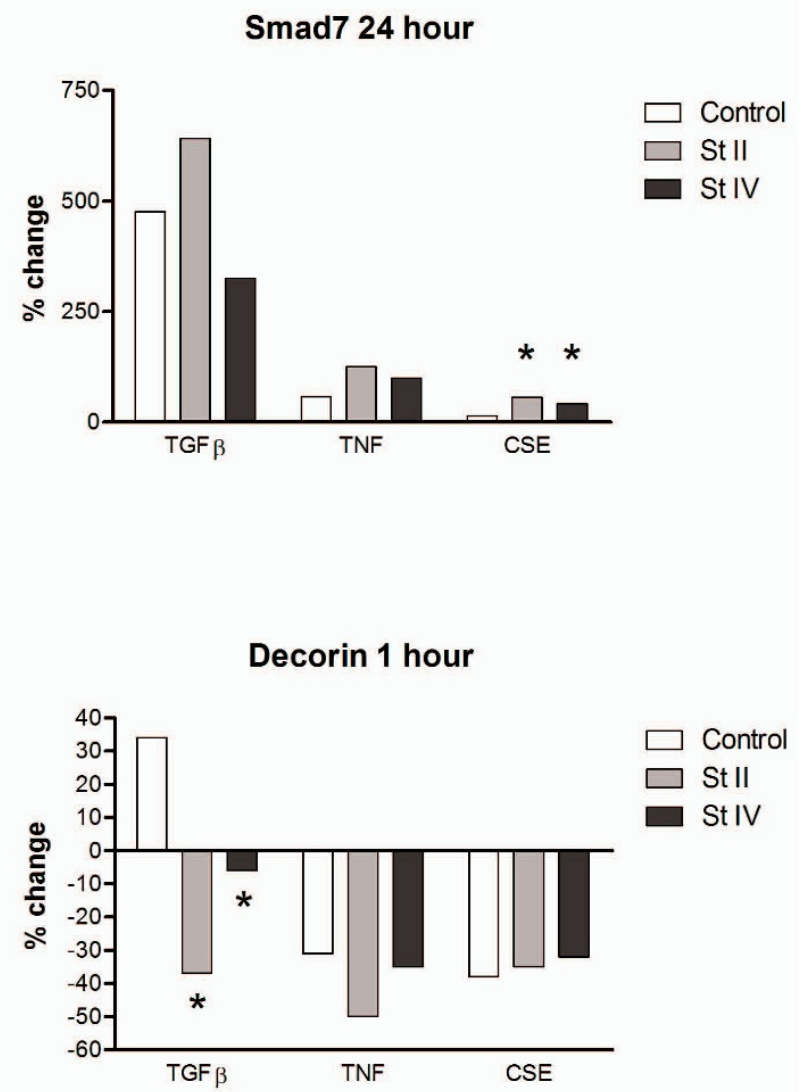

\section{Figure 4}

Differential gene expression in COPD fibroblasts compared to control fibroblasts. $X$-axis shows different stimuli, $y$-axis shows the percentage change of the $2^{\text {-delta-delta-Ct }}$ values from the stimulation compared to basal expression. Basal gene expression did not significantly differ between stage II, stage IV, or control fibroblasts for each of the different genes and time points. * indicates a significant difference between COPD and control fibroblasts. 
patients by TGF- $\beta$, TNF, and CSE, factors that are of prime importance in COPD development. We therefore first investigated the regulation of the Smad pathway in control fibroblasts and observed that TGF $\beta$ stimulation in general resulted in downregulation of Smad3 gene expression while Smad2, 4, 7, biglycan and versican gene expressions were upregulated. This downregulation of Smad3 gene expression by TGF $\beta$, together with the upregulation of Smad7 supports an inhibitory feedback mechanism because a reduced presence of Smad3 mRNA will result in reduced levels of Smad3 protein, as suggested previously [16]. Surprisingly, downregulation of Smad3 gene expression did not result in direct downregulation of ECM gene expression, but in contrast biglycan and versican gene expression was upregulated. This may be due to the fact that there is sufficient Smad3 protein available within the measured period of stimulation which subsequently activates ECM gene expression.

An unexpected finding was that TNF induced upregulation of Smad2, 4 and 7 mRNA in control fibroblasts after 24-hrs, similar to TGF $\beta$. Furthermore, TNF induced an early downregulation of biglycan and later downregulation of versican. TNF has been demonstrated to be able to inhibit ECM production by fibroblasts [26]. This is in accordance with the reduced biglycan and versican gene expression in our control fibroblasts. Based on our previous findings we can conclude that TGF $\beta$ is known [11] to have a stimulatory effect on the Smad pathway at the protein level, yet this effect is less clear for Smad-gene expression. As Smad proteins are rather stable intracellular proteins, stimulation of the Smad pathway may result in downstream increased production of extracellular matrix proteins without necessarily a direct upregulation of Smad-gene expression. However, the increased ECM protein end-product may lead to a negative feedback loop that affects the gene expression level. Furthermore, also the effect on the balance between the stimulating and inhibiting Smad gene products is of importance in relation to the actual resulting ECM production.

The second research question we addressed is whether the Smad pathway is differentially expressed under basal conditions in fibroblasts of COPD patients and control subjects. We observed no significant differences between the groups suggesting that the altered modulation of the ECM as observed in COPD is not due to intrinsic differences in basal expression levels of the Smad pathway genes in fibroblasts. We can not rule out that the basal gene expression is normalized due to culturing of the fibroblasts for several passages. However, our data show that these fibroblasts are still capable of responding to stimuli and this particularly uncovers the differential fibroblast response in COPD patients and controls.
The third question we addressed is whether the differences in ECM modulation as observed in COPD can be ascribed to a differential modulation of the Smad pathway under influence of COPD relevant cytokines and cigarette smoke, the most important etiologic risk factor of COPD. Stage II and IV COPD fibroblasts displayed up- and downregulation of Smad genes under influence of TGF $\beta$ and TNF in the same direction as the control fibroblasts. As CSE exposure mainly induced inhibition of expression, it seems likely that a general effect may play a role, although of course some of the presumed > 5000 cigarette smoke compounds also may have a specific role affecting certain receptors or downstream mediators. Importantly, CSE exposure induced differential effects on Smad4 and 7, and biglycan and decorin gene expression of COPD fibroblasts, findings that were not or only transiently observed in control fibroblasts. Apparently, fibroblasts of COPD patients are more reactive to components of cigarette smoke extract. Of importance to the pathogenesis of COPD, CSE blocked the repair effect of COPD pulmonary fibroblasts, as represented by a decreased Smad3 gene expression at 1 hour and Smad 4 expression at 24 hour, together with the elevated Smad7 gene expression at 24 hours. It has been demonstrated that CSE is capable to upregulate the expression of GADD34, a cell cycle related protein [27]. The inhibitory effect of Smad7 on Smad2 and/or Smad3 phosphorylation is most likely mediated via GADD34 [28]. This indicates that CSE is capable to induce decreased Smad2 and Smad3 activation by dephosphorylation of the TGF $\beta$ receptor I and thus is indirectly capable of inhibiting the ECM gene transcription. This is compatible with the observation that Smad3 deficiency in mouse knock-out models results in abnormal lung alveolarization resembling emphysema [29,30]. We also found increased expression of Smad7, the inhibitor of ECM production that can also be involved in proinflammatory actions $[31,32]$. Thus, it seems likely that ongoing smoking in susceptible individuals leads to continuous suppression of Smad3 activation and continuous stimulation of Smad7 gene expression, explaining chronic local suppression of tissue repair.

In contrast to the increased Smad7gene expression in our lung tissue fibroblasts, we previously demonstrated a reduced expression of Smad7 protein in bronchial epithelial cells of COPD patients compared to control subjects [33]. In addition, Springer et al. demonstrated a reduced Smad7 gene expression in bronchial biopsies of stage II COPD patients. This may be indicative for the fibrotic processes observed in COPD airways [34]. Springer and coworkers incubated a bronchial epithelial cell line with CSE for 48 hours and found a reduced Smad7 under these conditions, and concluded that cigarette smoke is a reducing factor for Smad7 expression [34]. Apparently, Smad7 regulation is dependent on the cell type and/or on the 
duration of stimulation because we found an increase in Smad7 gene expression in our primary parenchymal fibroblasts after 24 hours under influence of CSE. Together, the results of their study and ours match the outcome of fibrosis in the airways and excess ECM destruction in the parenchyma as observed in emphysema.

Lung fibroblasts from COPD patients as well as controls showed an upregulation of biglycan and versican gene expression after 24-hour TGF $\beta$ stimulation. This indicates that lung fibroblasts of COPD patients are capable of upregulating ECM genes on gene expression level, and the results depend on the effects of the local cytokine microenvironment and the presence of cigarette smoke. Of interest, and compatible with our previous observations, decorin gene expression was mainly downregulated in COPD fibroblasts, a finding that occurred with all stimuli, and only transiently at 1 hour after CSE in control fibroblasts. This highlights the putative important role of decorin in COPD.

Obviously our data are a first set of experiments that now need expansion at the protein level and including additional kinetic data. There are some limitations to our study since our experiments were focused on intracellular regulation, and hence it is not always clear whether the direction of the modulation is a direct result of the applied stimulus or the result of a cellular counteraction, as a response to upregulation of other cellular factors by this applied stimulus. Therefore, our data is conclusive as to our hypothesis that there is an aberrant regulation of the Smad pathway, but it is only supportive as to any conclusion of the exact underlying nature of this aberrant regulation.

In conclusion, our study in control and COPD fibroblasts shows similar regulation of the Smad pathway in COPD and controls without stimulation, but differential effects of particularly cigarette smoke on fibroblast expression of the Smad-genes, an intracellular pathway that is involved in regulation of ECM gene expression. TGF $\beta$, TNF, and CSE cause differential downregulation of decorin gene expression in COPD patients, at least partially via the Smad pathway. Our findings may explain why only a subset of smokers demonstrates an excess parenchymal ECM destruction under influence of cigarette smoking. Smad3, 4 and 7 have to be considered as important factors in the defective repair process of COPD fibroblasts, since smoke exposure affects expression of these genes in COPD but not in control fibroblasts. Because of the chronicity of COPD in combination with its slow progression, even subtle differences in this pathway can have a great impact in the outcome of the disease.

\section{Abbreviations}

ECM: Extracellular matrix; COPD: Chronic Obstructive Pulmonary Disease; TGF $\beta$ : Transforming Growth Factor $\beta$; TNF: Tumor Necrosis Factor; CSE: Cigarette Smoke Extract; GOLD: Global initiative for Chronic Obstructive Lung Disease; FEV1: Forced Expiratory Volume in 1 second; Ct: Concentration in Time

\section{Competing interests}

The authors declare that they have no competing interests.

\section{Authors' contributions}

AZ carried out the data analysis and drafted the manuscript. DP and WT participated in the design of the original study, were responsible for clinical and histological patient data and contributed substantially to the manuscript. MRJ and AZ carried out real-time PCR. MRJ, JAN and JTWMV carried out the fibroblast isolations and culture and stimulation experiments and contributed to the manuscript.

\section{Additional material}

\section{Additional file 1}

Results of real-time PCR analysis 1 and $24 \mathrm{~h}$, GOLD stage II and IV and control. The data provided represent results of real-time PCR analysis at 1 and $24 \mathrm{~h}$, presented for control and disease stage, and per gene of interest and per stimulation. Values are based on 2-delta-delta-Ct values. Click here for file

[http://www.biomedcentral.com/content/supplementary/14659921-9-83-S1.doc]

\section{Acknowledgements}

This study was supported by an unrestricted grant from the Dutch Asthma Foundation, grant number 3.2.02.47

\section{References}

I. Barnes PJ, Shapiro SD, Pauwels RA: Chronic obstructive pulmonary disease: molecular and cellular mechanisms. Eur Respir J 2003, 22:672-688.

2. Barnes PJ: Mediators of chronic obstructive pulmonary disease. Pharmacol Rev 2004, 56:515-548.

3. Reid L: Measurement of the bronchial mucous gland layer: a diagnostic yardstick in chronic bronchitis. Thorax 1960, I5:|32-I4I.

4. Wright JL, Lawson LM, Pare PD, Kennedy S, Wiggs B, Hogg JC: The detection of small airways disease. Am Rev Respir Dis 1984, 1 29:989-994.

5. Hogg JC, Chu F, Utokaparch S, Woods R, Elliott WM, Buzatu L, Cherniack RM, Rogers RM, Sciurba FC, Coxson HO, et al.: The nature of small-airway obstruction in chronic obstructive pulmonary disease. N Engl J Med 2004, 350:2645-2653.

6. Leopold JG, Gough J: The centrilobular form of hypertrophic emphysema and its relation to chronic bronchitis. Thorax 1957, 1 2:219-235.

7. McLean KH: The histology of generalized pulmonary emphysema. I. The genesis of the early centrolobular lesion: focal emphysema. Australas Ann Med 1957, 6: I24-I 40.

8. McLean KH, Gough J: The histology of generalized pulmonary emphysema. II. Diffuse emphysema. Australas Ann Med 1957, 6:203-217. 
9. Geld YM van der, van Straaten JF, Postma DS, Timens W: Role of proteoglycans in the development and pathogenesis of emphysema. In Proteoglycans in lung disease 168th edition. Edited by: Garg HG, Roughley PJ, Hales CA. New York: Marcel Dekker, Inc; 2002:24I-267.

10. Roberts $A B$, McCune BK, Sporn MB: TGF-beta: regulation of extracellular matrix. Kidney Int 1992, 41:557-559.

II. Schiller M, Javelaud D, Mauviel A: TGF-beta-induced SMAD signaling and gene regulation: consequences for extracellular matrix remodeling and wound healing. J Dermatol Sci 2004, 35:83-92.

12. van Straaten JF, Coers W, Noordhoek JA, Huitema S, Flipsen JT, Kauffman HF, Timens W, Postma DS: Proteoglycan changes in the extracellular matrix of lung tissue from patients with pulmonary emphysema. Mod Pathol I 999, I 2:697-705.

13. Rabe KF, Hurd S, Anzueto A, Barnes PJ, Buist SA, Calverley P, Fukuchi Y, Jenkins C, Rodriguez-Roisin R, van Weel C, et al:: Global strategy for the diagnosis, management, and prevention of chronic obstructive pulmonary disease: GOLD executive summary. Am J Respir Crit Care Med 2007, 176:532-555.

14. Noordhoek JA, Postma DS, Chong LL, Menkema L, Kauffman HF, Timens W, van Straaten JF, Geld YM van der: Different modulation of decorin production by lung fibroblasts from patients with mild and severe emphysema. COPD 2005, 2(I): 17-25

15. Yamane K, Ihn H, Asano Y, Jinnin M, Tamaki K: Antagonistic effects of TNF-alpha on TGF-beta signaling through down-regulation of TGF-beta receptor type II in human dermal fibroblasts. J Immunol 2003, I 7I:3855-3862.

16. Camoretti-Mercado B, Solway J: Transforming growth factorbetal and disorders of the lung. Cell Biochem Biophys 2005, 43: $|3|-\mid 48$

17. Verrecchia F, Chu ML, Mauviel A: Identification of novel TGFbeta/Smad gene targets in dermal fibroblasts using a combined cDNA microarray/promoter transactivation approach. J Biol Chem 200I, 276: I 7058-17062.

18. Ten Dijke P, Hill CS: New insights into TGF-beta-Smad signalling. Trends Biochem Sci 2004, 29:265-273.

19. Itoh S, Itoh F, Goumans MJ, Ten Dijke P: Signaling of transforming growth factor-beta family members through Smad proteins. Eur J Biochem 2000, 267:6954-6967.

20. Ten Dijke P, Goumans MJ, Itoh F, Itoh S: Regulation of cell proliferation by Smad proteins. / Cell Physiol 2002, I 9 I:I-16.

21. Massague J: How cells read TGF-beta signals. Nat Rev Mol Cell Biol 2000, I: 169-178.

22. Di Stefano A, Caramori G, Ricciardolo FL, Capelli A, Adcock IM, Donner CF: Cellular and molecular mechanisms in chronic obstructive pulmonary disease: an overview. Clin Exp Allergy 2004, 34: II56-II67.

23. Barnes PJ: New concepts in chronic obstructive pulmonary disease. Annu Rev Med 2003, 54:II3-I29.

24. Noordhoek JA, Postma DS, Chong LL, Vos JT, Kauffman HF, Timens W, van Straaten JF: Different proliferative capacity of lung fibroblasts obtained from control subjects and patients with emphysema. Exp Lung Res 2003, 29:291-302.

25. Livak KJ, Schmittgen TD: Analysis of relative gene expression data using real-time quantitative PCR and the 2(-Delta Delta C(T)) Method. Methods 200I, 25:402-408.

26. Fujita M, Shannon JM, Morikawa O, Gauldie J, Hara N, Mason RJ: Overexpression of tumor necrosis factor-alpha diminishes pulmonary fibrosis induced by bleomycin or transforming growth factor-beta. Am J Respir Cell Mol Biol 2003, 29:669-676.

27. Bosio A, Knorr C, Janssen U, Gebel S, Haussmann HJ, Muller T: Kinetics of gene expression profiling in Swiss 3T3 cells exposed to aqueous extracts of cigarette smoke. Carcinogenesis 2002, 23:74|-748.

28. Shi W, Sun C, He B, Xiong W, Shi X, Yao D, Cao X: GADD34-PP Ic recruited by Smad7 dephosphorylates TGF\{beta\} type receptor. J Cell Biol 2004, 164:29I-300.

29. Chen H, Sun J, Buckley S, Chen C, Warburton D, Wang XF, Shi W: Abnormal mouse lung alveolarization caused by Smad3 deficiency is a developmental antecedent of centrilobular emphysema. Am J Physiol Lung Cell Mol Physiol 2005, 288:L683-L69I.

30. Bonniaud P, Kolb M, Galt T, Robertson J, Robbins C, Stampfli M, Lavery C, Margetts PJ, Roberts AB, Gauldie J: Smad3 null mice develop airspace enlargement and are resistant to TGF- beta-mediated pulmonary fibrosis. J Immunol 2004, I 73:2099-2108.

31. Monteleone G, Kumberova A, Croft NM, McKenzie C, Steer HW, MacDonald TT: Blocking Smad7 restores TGF-betal signaling in chronic inflammatory bowel disease. J Clin Invest 2001, 108:601-609.

32. Nakao A, Miike S, Hatano M, Okumura K, Tokuhisa T, Ra C, Iwamoto I: Blockade of transforming growth factor beta/Smad signaling in T cells by overexpression of Smad7 enhances antigeninduced airway inflammation and airway reactivity. J Exp Med 2000, 192:15I-158.

33. Zandvoort A, Postma DS, Jonker MR, Noordhoek JA, Vos JT, Geld YM van der, Timens W: Altered expression of the Smad signalling pathway: implications for COPD pathogenesis. Eur Respir J 2006, 28:533-54|.

34. Springer J, Scholz FR, Peiser C, Groneberg DA, Fischer A: SMADsignaling in chronic obstructive pulmonary disease: transcriptional down-regulation of inhibitory SMAD 6 and 7 by cigarette smoke. Biol Chem 2004, 385:649-653.

35. Nakao A, Okumura K, Ogawa H: Smad7: a new key player in TGF-beta-associated disease. Trends Mol Med 2002, 8:36I-363.

36. Demoor-Fossard M, Galera P, Santra M, lozzo RV, Pujol JP, Redini F: A composite element binding the vitamin $D$ receptor and the retinoic $\times$ receptor alpha mediates the transforming growth factor-beta inhibition of decorin gene expression in articular chondrocytes. J Biol Chem 200I, 276:36983-36992.
Publish with Biomed Central and every scientist can read your work free of charge

"BioMed Central will be the most significant development for disseminating the results of biomedical research in our lifetime. "

Sir Paul Nurse, Cancer Research UK

Your research papers will be:

- available free of charge to the entire biomedical community

- peer reviewed and published immediately upon acceptance

- cited in PubMed and archived on PubMed Central

- yours - you keep the copyright 